\title{
Conjugated Linoleic Acid n-7
}

National Cancer Institute

\section{Source}

National Cancer Institute. Conjugated Linoleic Acid n-7. NCI Thesaurus. Code C68337.

A polyunsaturated long-chain fatty acid with an 18-carbon backbone and exactly two double bonds, originating from the 9th and 11th positions from the methyl end, resulting in a conjug ated section of the acyl chain. Three stereoisomers of conjug ated linoleic acid, n-7 are recognized. 